\title{
A (im)possível identidade de aprendizes de língua inglesa: um estudo discursivo das formas de resistência em sala de aula
}

\author{
Vaniele Medeiros da Luz \\ Universidade do Sul de Santa Catarina - UNISUL
}

\begin{abstract}
Resumo
Nosso propósito neste estudo é verificar e compreender formas de resistência que se manifestam durante o processo de ensino-aprendizagem de língua inglesa (LI). O objeto de pesquisa é contextualizado a partir das bases teóricas da Análise de Discurso e dos Estudos Culturais. O corpus foi constituído por enunciados emitidos pelos alunos durante algumas situações de sala de aula e por enunciados formulados como resposta a perguntas de um questionário e de entrevistas. A interpretação dos dados permitiu concluir que embora os discursos dos aprendizes produzidos em situações de entrevistas e questionário reproduzam estereótipos inscritos na memória discursiva acerca da importância do ensino e aprendizado de LI, discursos e outras práticas produzidas revelam formas de resistência a esse aprendizado.
\end{abstract}

Palavras-chave: resistência; ensino-aprendizagem de Inglês como língua estrangeira; identificação; poder.

\begin{abstract}
The purpose of this study is to verify and understand forms of resistance that arise during the teaching-learning of the English language. The object of the research is contextualized from the theoretical bases of Discourse Analysis and Cultural Studies. The corpus consists of statements made by students during classroom situations and answers to questions on a questionnaire and in interviews. The interpretation of the data showed that, although the discourse produced by learners in situations such as questionnaires and interviews portrays stereotypes incorporated in their discourse memory about the importance of teaching and learning LI, their discourse and other kinds of practice point to manifestations of resistance to this learning.
\end{abstract}

Keywords: resistance, teaching and learning of English as a foreign language; identification; power

\section{INTRODUÇÃO}

O Inglês, nos dias atuais, goza de uma posição dominante em muitos setores da ciência, comunicação, cultura de massa, imagética e da inovação tecnológica. Do ponto de vista linguístico, o Inglês, segundo Rajagopalan (2003, p. 12 apud DENARDIN, 2010, p. 6), não é somente uma língua, mas já passou a ser tratado como uma commodity, ou seja, "uma mercadoria em torno da qual está sendo construído um poderoso fetichismo". Não é preciso ir 
muito longe para observarmos a presença da Língua Inglesa em nosso cotidiano, desde os materiais impressos até a Internet; dos estabelecimentos comerciais até nossas próprias vestimentas. Diante disso, resulta um poder de atração junto a todos aqueles, anglófonos ou não, que buscam ascensão social, melhores oportunidades de trabalho e sucesso profissional.

Face a esse discurso institucionalizado de valorização da Língua Inglesa, um estudante tem vários motivos para aprender o idioma. No entanto, apesar dos objetivos que justificam a aprendizagem dessa língua estrangeira (LE) ${ }^{1}$, observamos, constantemente, uma contradição entre os discursos institucionalizados que circundam o ambiente escolar e as práticas, tanto docentes quanto discentes.

Pretendemos, neste artigo, apresentar parte de uma pesquisa desenvolvida para uma dissertação de mestrado. As primeiras ideias para realizar o trabalho originaram-se de comentários e reclamações de meus alunos, tanto na rede pública quanto privada de ensino, em face do aprendizado de Língua Inglesa: "não se aprende Inglês na escola"; "pra que eu devo saber Inglês?”; “eu não sei Inglês"; “eu não sei ler em Inglês"; "Inglês é muito difícil”. Além disso, observamos com frequência, durante minhas aulas, uma baixa participação dos alunos, ainda que esta fosse estimulada e priorizada pelos princípios pedagógicos da escola. Todos esses discursos observados, associados à recusa de participação nas aulas e outras práticas, foram tratados, neste estudo, como formas de resistência.

Tendo em vista as situações apresentadas, ensejamos duas perguntas que configuraram respectivamente o problema geral e o específico desse estudo: Quais são as 'possíveis' causas das formas de resistência que estudantes de Ensino Médio, da rede pública, manifestam ao aprendizado de Língua Inglesa como língua estrangeira? Como essas formas de resistência se manifestam?

Portanto, foi na tentativa de responder a esses questionamentos que desenvolvemos a pesquisa. O objetivo geral norteador, de caráter descritivo e interpretativo, foi verificar e explicar causas ${ }^{2}$ possíveis que levam estudantes de ensino regular formal, da rede pública, a apresentar formas de resistência ao aprendizado de Língua Inglesa como língua estrangeira. O objetivo específico foi identificar formas/atitudes de resistência que

\footnotetext{
${ }^{1}$ Está sendo feita aqui a distinção entre segunda língua e língua estrangeira no que se refere ao contexto de ensino-aprendizagem. Aprender Inglês como segunda língua significa aprendê-lo em contexto de imersão, enquanto que aprender o idioma como língua estrangeira significa aprendê-lo em seu contexto de origem. Um brasileiro estudando inglês nos EUA está aprendendo uma segunda língua, enquanto um brasileiro estudando inglês no Brasil está aprendendo uma LE.

2 Embora, nesta pesquisa, estejamos utilizando a palavra 'causa', que parece estar relacionada às ciências exatas, implicando uma mecânica do tipo causa = resultado; aqui, 'causa' está relacionada a contextos históricoideológicos que podem e/ou poderiam motivar as formas de resistência que pretendemos submeter à investigação/interpretação.
} 
estudantes de ensino regular formal, da rede pública, apresentam durante aulas de Língua Inglesa como língua estrangeira.

Para dar conta desses objetivos, identificamos o trabalho aos pressupostos de duas grandes bases teóricas: a Análise de Discurso e os Estudos Culturais. A primeira identificação é com a Análise de Discurso (AD), na tentativa de conectar o linguístico (a manifestação das múltiplas marcas linguísticas nos enunciados dos estudantes de Inglês da escola pública) ao discursivo (discursos constituem identidades de aprendizes de línguas) num pano de fundo social e ideológico, que resulta na interpretação dos efeitos de sentido do dito e do não-dito na experiência de aprender línguas. A segunda identificação relaciona-se com a noção de identidade, entendida como o construto sóciocultural, permeável e inconcluso que se verifica no mundo globalizado contemporâneo.

Noções como subjetividades, identidades e discursos são de grande valia para a pesquisa, já que a aprendizagem de uma língua estrangeira insere o sujeito em outra discursividade. O contato com o estrangeiro pode conduzir a "uma recusa da própria cultura, reforçada por uma admiração sem limites pelo país do outro, ou a uma revolta inconsciente e improdutiva." (PERUCHI; CORACINI, 2003, p. 377) E são essas relações com o estrangeiro que nos propomos a investigar.

\section{FUNDAMENTAÇÃO TEÓRICA}

\section{A Análise de Discurso}

Existem muitas maneiras de estudar a linguagem; podemos fazer recair a atenção sobre a língua enquanto sistema de signos - como o faz a linguística - ou como sistema de regras do bem falar e escrever - como o faz a gramática, por exemplo. A Análise de Discurso (doravante $\mathrm{AD}$ ), de linha francesa, não trata da língua, nem da gramática, embora também não as exclua. Ela trata do discurso e, como assevera Orlandi (2002), a palavra 'discurso', etimologicamente, designa a ideia de curso, de percurso, de movimento, abertura para os múltiplos sentidos. "O discurso é assim palavra em movimento, prática de linguagem: com o estudo do discurso observa-se o homem falando.” (ORLANDI, 2002, p. 15)

$\mathrm{O}$ que mais interessa à $\mathrm{AD}$ é a linguagem tomada como prática, trabalho simbólico, o reconhecimento de sua função pelo confronto ideológico, e não como mero instrumento de comunicação. Ao falar, ao significar, o sujeito também se significa. Sujeitos e sentidos só existem a partir de relações, 'efeitos', e não podem ser tratados como se já fossem existentes em si. É só pelo efeito ideológico que sentidos e sujeitos, ilusoriamente, estão já-lá, a priori. Conforme Orlandi (2002, p. 15), "na análise de discurso, procura-se compreender a 
língua fazendo sentido, enquanto trabalho simbólico, parte do trabalho social geral, constitutivo do homem e da sua história.”. Portanto, por meio da Análise do Discurso, conhecemos melhor a capacidade de significar e de nos significarmos, porque ela serve como mediação entre o homem e a realidade natural e social onde está inserido. Tal mediação torna possível a transformação do homem e de sua realidade.

Há muitos conceitos pertinentes dentro da conjuntura teórica da $\mathrm{AD}$, entretanto nos ateremos, aqui, à teorização de sujeito, uma vez que o consideramos ponto de ancoragem e determinante de muitos outros aspectos-chave para a pesquisa.

\section{Língua e Discurso}

A língua, na Análise do Discurso, é vista como um sistema sujeito a falhas, e a ideologia como constitutiva do sujeito e da produção de sentidos. Seu objeto de estudo é o discurso. A noção de discurso não se assemelha à noção de parole referida por Saussure (2006), mas só pode ser formulada se entendemos o uso que fazemos da língua. Desse modo, a $\mathrm{AD}$ resgata, por meio do discurso, o sujeito e o significado deixados de lado pela Linguística: "mais do que um resultado, o discurso vai definir um processo de significação no qual estão presentes a língua e a história, em suas materialidades, e o sujeito, devidamente interpelado pela ideologia." (FERREIRA, 2003, p. 203, grifo do autor). O discurso pode, então, ser definido como a palavra em movimento, prática de linguagem que se realiza entre sujeitos, num determinado contexto.

O discurso não obedece ao esquema tradicional de comunicação, que concebe a língua de modo estanque e os sujeitos como objetos de transmissão e decodificação de informações. Para a Análise do Discurso, não há separação entre emissor e receptor, tudo se realiza simultaneamente e não há transmissão de informações, mas efeitos de sentido.

Os efeitos de sentido a que nos referimos são os diferentes sentidos que os sujeitos podem formular de acordo com a formação discursiva a que estão identificados no momento, em sua relação histórica com o(s) outro(s). Isso implica dizer que os sentidos não existem em si mesmos, não são produtos acabados, mas estão em curso e podem mudar de acordo com a formação ideológica dos interlocutores.

Quando dizemos que no discurso há efeitos de sentido, queremos dizer que as palavras, as expressões, as proposições, mudam de sentido dependendo das posições de quem as emprega e de quem as interpreta. Como o exemplo citado por Orlandi (2002, p. 45), "“[... a palavra "terra" não significa o mesmo para um índio, para um agricultor sem terra e para um grande proprietário rural”. Configuram-se aí as formações discursivas e ideológicas reguladoras da produção e recepção dos sentidos. 
É assim que a ideologia, em $\mathrm{AD}$, é pensada como um mecanismo estruturante do processo de significação, pois determina a constituição dos sentidos, uma vez que o sentido não existe em si, mas é produzido a partir das posições ideológicas colocadas em jogo no processo discursivo. Esse mecanismo ideológico, ligado ao modo de produção dominante em uma formação social, é que garantirá, por sua vez, a reprodução das relações de produção que aí se constituem. A esse conjunto complexo de atitudes e de representações que não são nem individuais nem universais, mas se relacionam mais ou menos diretamente à posição de classes em conflito umas com as outras, é que se denomina formação ideológica (FI). E uma FI tem, por seu turno, como seus componentes, formações discursivas (FD).

A formação discursiva, por sua vez, se refere a uma determinada formação ideológica projetada na linguagem. Em Semântica e Discurso, Pêcheux chama de formação discursiva "aquilo que, numa formação ideológica dada, isto é, a partir de uma posição dada numa conjuntura dada, determinada pelo estado da luta de classes, determina o que pode $e$ deve ser dito" (PÊCHEUX, 2009, p. 147, grifo do autor).

Por aí percebemos que as palavras adquirem sentido a partir das formações discursivas nas quais se inscrevem. Orlandi (2002) vai dizer que as FD, por isso, “podem ser vistas como regionalizações do interdiscurso, configurações específicas dos discursos em suas relações" (p. 43), lembrando que as FD não podem ser pensadas "como blocos homogêneos funcionando automaticamente. Elas são constituídas pela contradição, são heterogêneas nelas mesmas e suas fronteiras são fluidas, configurando-se e reconfigurando-se continuamente em suas relações" (p. 44). É neste sentido que Indursky (2007) tratará de uma FD cujas fronteiras são bastante porosas, permitindo a entrada de saberes estranhos e colocando em jogo, dessa forma, a unicidade da forma-sujeito.

\section{Forma-sujeito do discurso}

O sujeito do discurso tem essa peculiaridade, segundo Orlandi (2002), de, ao mesmo tempo, ser "sujeito de" e estar "sujeito a". Ao dizer que o sujeito é "sujeito de" a autora está se referindo ao desejo inconsciente que o constitui, e estar "sujeito a" representa a submissão desse sujeito à ideologia através de sua relação constitutiva com a língua e com a história, pois ele "é afetado por elas" (ORLANDI, 2002, p. 49) ao produzir sentidos. Isso mostra que na $\mathrm{AD}$ não há um sujeito centrado; nem um sujeito totalmente submisso, pois ele não é apenas reprodutor de sentidos na medida em que também é capaz de alterar sentidos e produzir o novo. A noção de sujeito em $\mathrm{AD}$ está intrinsecamente relacionada ao exterior que o constitui e não a um indivíduo plenamente consciente do que diz. 
A noção de sentido está, também, relacionada à exterioridade, pois os sentidos são produzidos na discursividade, isto é, estão condicionados às posições ideológicas às quais os sujeitos encontram-se submetidos. E o sujeito de discurso, de dimensão ideológica, é, na verdade, uma forma-sujeito ${ }^{3}$; uma forma-sujeito histórica.

Conforme Pêcheux (2009), o sujeito do discurso se identifica a uma formação discursiva que o constitui e, ao formular o intradiscurso, simula o interdiscurso, de modo que o interdiscurso aparece como o 'já-dito', e é isso que produzirá os efeitos de sentido e os efeitos de evidência e literalidade. Podemos caracterizar a forma-sujeito como realizando a incorporação-dissimulação do interdiscurso no intradiscurso.

Vale a pena lembrar que, segundo propõe Pêcheux (2006, p. 56-57, grifos do autor), "não há identificação plenamente bem sucedida, isto é, ligação sócio-histórica que não seja afetada, de uma maneira ou de outra, por uma 'infelicidade' no sentido performativo do termo - isto é, no caso, por um 'erro de pessoa', isto é, sobre o outro, objeto de identificação". Ou seja, não há processo de interpelação do sujeito que se realize em plenitude. Daí o sujeito relutar e resistir ante as formas de poder estabelecidas.

\section{Poder e Resistência}

A noção de sujeito, no pensamento foucaultiano, rompe com o referencial utilizado pela tradição filosófica, rejeitando a noção de sujeito transcendental e seu papel unificador dos enunciados como discursos de verdade. Para Foucault, não há sujeito como fundador, agente de enunciação de verdade. O sujeito não é portador de uma essência nem possui caráter universal, pois não há uma verdade oculta, uma origem a ser buscada. Para ele, o sujeito não é jamais uma substância,

[...] é uma forma, e essa forma nem sempre é, sobretudo, idêntica a si mesma. Você não tem consigo próprio o mesmo tipo de relações quando você se constituiu como sujeito político que vai votar ou toma a palavra em uma assemléia [sic], ou quando você busca realizar o seu desejo em uma relação sexual. Há, indubitavelmente, relações e interferências entre essas diferentes formas de sujeito; porém, não estamos na presença do mesmo tipo de sujeito. Em cada caso, se exercem, se estabelecem consigo mesmo formas de relação diferentes. E o que me interessa é, precisamente, a constituição histórica dessas diferentes formas do sujeito, em relação aos jogos de verdade. (FOUCAULT, [1984] 2010b, p. 275)

Assim, Foucault concebe um sujeito que se constitui nas relações de poder e nos procedimentos de verdade, ou seja, por meio de práticas de assujeitamento e práticas de liberdade. Trata-se de um sujeito dual, aquele que é assujeitado a alguém pelas técnicas de

\footnotetext{
${ }^{3}$ A expressão "forma-sujeito", segundo Pêcheux (2009), foi introduzida por L. Althusser: "[...] "Todo indivíduo humano, isto é, social, só pode ser agente de uma prática se se revestir da forma de sujeito. A 'forma-sujeito', de fato, é a forma de existência histórica de qualquer indivíduo, agente das práticas sociais". (PÊCHEUX, 2009, p. 150)
} 
controle (objetivação) e também aquele preso à sua própria identidade por uma consciência de si (subjetivação). Interessa menos para o autor saber o que o ser humano é, mas saber como se constitui a partir de suas práticas.

Em A história da sexualidade, volume I - A vontade de saber, Foucault (1999) escreveu que, ao falar a verdade sobre si mesmo, o sujeito tinha a possibilidade de conhecerse, ao mesmo tempo em que se tornava também exposto aos outros, num entrecruzamento dos discursos que definem as nossas verdades sobre nós mesmos e a nossa subjetividade.

Daí reside a afirmação de que o sujeito é constituído e determinado a partir de relações de poder e saber; relações que , por serem históricas, são passíveis de transformação e enfraquecimentos. Nesse sentido, apesar de constituído pelos eixos poder/saber, o sujeito tem condições de questionar seus limites, e é a partir da percepção do que se é possível transpor e transformar, que a liberdade tem condições de existir.

Em se tratando de liberdade, para Foucault, o poder apresenta-se em circularidade e faz-se presente em todas as relações que pressupõem liberdade. Para pensarmos o poder a partir de Foucault, buscamos respaldo teórico, além de em outras obras, principalmente em $A$ ordem do discurso.

Nessa obra, Foucault (2010a) faz reflexões sobre o poder que produz, controla e reorganiza o saber na sociedade. Toda a análise sobre as coerções que recaem sobre a produção de discursos aponta para duas importantes teses. Em primeiro lugar, o poder, antes de ser negativo, é considerado como uma relação de forças. Por conta dessa especificidade, o poder está em todas as partes, de tal modo que os sujeitos são atravessados por relações de poder, não estando independentes delas. Em segundo lugar, o poder não somente reprime, mas também produz efeitos de verdade e saber, constituindo verdades, práticas e subjetividades.

É a partir da análise desses dispositivos de controle de ordem discursiva, que Foucault rejeita uma concepção idealista de sujeito, isto é, de sujeito livre (não determinado pela exterioridade), que exprimiria um sentido preexistente, refletido pela linguagem.

Voltando à questão do poder - conceito nodal desta seção - para Foucault (1999), o poder não é algo que se adquire, que se guarda ou se deixa escapar, mas é algo que se exerce em meio a relações.

[...] as relações de poder não se encontram em posição de exterioridade com respeito a outros tipos de relações [...], mas lhe são imanentes; [...] as relações de poder não estão em posição de superestrutura, com um simples papel de proibição ou de recondução; possuem lá onde atuam, um papel diretamente produtor; [...] o poder vem de baixo; isto é, não há, no princípio das relações de poder, e como matriz geral, uma oposição binária e global entre os dominadores e os dominados, [...] as relações de poder são, ao mesmo tempo, intencionais e não subjetivas [...] lá onde há poder há resistência e, no entanto [...] esta nunca se encontra 
em posição de exterioridade em relação ao poder. [...] Esses pontos de resistência estão presentes em toda a rede de poder. (FOUCAULT, 1999, p. 90-91)

Refinando essa compreensão, podemos dizer que o poder, em Foucault, não advém de um 'rei', ou seja, que o poder emana de uma fonte que o detém e pode deixá-lo fluir. Contudo, "o poder deve ser analisado como algo que [...] só funciona em cadeia. Nunca está localizado aqui ou ali, nunca está nas mãos de alguns, nunca é apropriado como uma riqueza ou um bem. O poder funciona e se exerce em rede.” (FOUCAULT, 2004, p. 183)

\section{Silêncio e resistência}

Segundo Orlandi (2007), "o silêncio é [...] a "respiração" (o fôlego) da significação; um lugar de recuo necessário para que se possa significar, para que o sentido faça sentido. Reduto do possível, do múltiplo, o silêncio abre espaço para o que não é "um", para o que permite o movimento do sujeito". (ORLANDI, 2007, p.13)

O sentido não é fixo, ele não está preso a algum lugar pré-definido, não está "atrás" das palavras. Ele é construído nas relações entre locutores, já que sentidos e sujeitos se constroem mutuamente, no jogo das múltiplas formações discursivas. As diferentes formações discursivas "recortam o interdiscurso (o dizível, a memória do dizer) e refletem as diferenças ideológicas, o modo como as posições dos sujeitos, seus lugares sociais aí representados, constituem sentidos diferentes." (ORLANDI, 2007, p. 20). Para analisar o silêncio e os mecanismos discursivos do silêncio, é necessário estudar as formações discursivas. Sabendo que é no silêncio que o movimento dos sentidos é possível e que as diferentes formações discursivas podem ser transpostas. "[...] o limite de uma formação discursiva é o que a distingue de outra (logo, é o mesmo limite da outra), o que permite pensar [...] que a formação discursiva é heterogênea em relação a ela mesma, pois já evoca por si o 'outro' sentido que ela não significa.” (ORLANDI, 2007, p. 21). É aí que se encontra o trabalho com o silêncio, no funcionamento do equívoco, do non-sens, do sentido "outro".

Para Orlandi (2007), o silêncio é "a possibilidade para o sujeito de trabalhar sua contradição constitutiva, a que o situa na relação do 'um' com o 'múltiplo', a que aceita a reduplicação e o deslocamento que nos deixam ver que todo discurso sempre se remete a outro discurso que lhe dá realidade significativa." (p. 23) Orlandi (2007) classifica dois funcionamentos principais no trabalho com o silêncio: o silêncio fundador, aquele constitutivo da linguagem, e de todas as palavras, significando o não-dito e dando espaço de recuo significante; e a política do silêncio, subdividida em silêncio constitutivo e silenciamento. No silêncio constitutivo, esboça-se a ideia de que todo dizer cala alguma coisa, diz-se (y) para significar (x), ou seja, todo dizer tem sentidos silenciados. Na política do silêncio, trabalha-se 
com a concepção de que alguns sentidos são censurados ou pelo sujeito de uma formação discursiva, ou para toda uma comunidade em algum local historicamente determinado. "Em face dessa sua dimensão política, o silêncio pode ser considerado tanto parte da retórica da dominação (a da opressão) como de sua contrapartida, a retórica do oprimido (a da resistência)." (ORLANDI, 2007, p. 29). Esse é o caso de nossos sujeitos investigados. Os alunos estão de tal forma submetidos a determinadas formações discursivas que não conseguem transpô-las, a não ser através do silêncio. O silêncio se torna, então, o (um dos) local (locais) de resistência.

Passamos agora à segunda base teórica que também sustenta nossa análise.

\section{Os Estudos Culturais}

Segundo Longaray (2005), investigações contemporâneas de inspiração sociocultural, realizadas na área da ASL (Aquisição de segunda língua), têm apresentado uma perspectiva mais crítica em relação ao aprendiz de línguas. Para a autora, "de acordo com essa nova postura acolhida por muitos pesquisadores da ASL, o aprendiz de línguas passa a ser aceito como um ser complexo - detentor de uma identidade mutável através do tempo e espaço". (LONGARAY, 2005, p.18). Neste estudo, seguindo a linha teórica de Norton (1995), serão considerados os conceitos de identidade e investimento, com o objetivo de estabelecer uma relação entre a noção de identidade social e o aprendizado de línguas. Da mesma maneira, serão trabalhados conceitos de motivação para traçar um comparativo entre motivação e investimento. Embora os estudos de Norton (1995) estejam voltados a aquisição de segunda língua, compreendemos que os conceitos abordados em sua pesquisa são igualmente relevantes para a nossa pesquisa, que trata de aprendizagem de língua estrangeira.

Norton (1995) inicia sua análise afirmando que os teóricos da ASL encontram dificuldades em estabelecer uma relação entre o aprendiz de línguas e o mundo social, ou seja, sugerindo a falta de uma teoria da identidade social que fosse capaz de manter tal relação. A pesquisadora, então, indica que a concepção de identidade social é múltipla e sujeita a mudança, ao mesmo tempo que propõe conceitos de investimento em oposição ao de motivação.

Ela ainda assevera que não há na literatura sobre motivação uma explicação consistente de como as variáveis afetivas interagem com o contexto social, tampouco o contexto social é considerado. Além disso, os teóricos não conseguiram constatar por que um aluno pode estar motivado, mostrando-se confiante e extrovertido e, às vezes, desmotivado, mostrando-se ansioso e introvertido. Também não é apresentado, nessas teorias, um 
argumento consistente sobre por que um aluno fala em sala de aula e, outras vezes, permanece em silêncio, no sentido da participação.

No âmbito da ASL, o conceito de motivação estava, segundo Norton (1995), ligado ao campo da psicologia social, no qual se tentava quantificar o comprometimento do aprendiz no processo da aprendizagem de segunda língua. Citados pela autora, Gardner e Lambert (1972 apud NORTON, 1995, p. 16) e Gardner (1985 apud NORTON, 1995, p. 17) são responsáveis pela introdução das noções de motivação instrumental e motivação integrativa. De acordo com Norton (1995), a motivação instrumental diz respeito ao desejo de aprender uma segunda língua com propósitos funcionais, como obter um emprego, por exemplo. Já a motivação integrativa, refere-se ao desejo do aprendiz de adquirir uma língua que auxilie a integração bem-sucedida do aprendiz à comunidade da língua-alvo.

Essas concepções de motivação são criticadas por Norton (1995) porque não dão conta de explicar a relação existente entre as relações de poder, identidade e aprendizado de línguas. Do ponto de vista de Norton (1995), "the conception of investment rather than motivation more accurately signals the socially and historically constructed relationship of the women to the target language and their sometimes ambivalent desire to learn and practice it ${ }^{4}$,. (p. 17)

Assim, a autora sinaliza que a noção de investimento pode ser melhor compreendida por meio da metáfora de capital cultural utilizada por Bourdieu (1977 apud NORTON, 1995, p. 17). O autor utiliza a expressão para se referir ao conhecimento e aos pensamentos que caracterizam diferentes grupos e classes em relação a conjuntos específicos de formas sociais. Segundo ele, determinadas formas de capital cultural possuem valor de troca mais alto dentro de um determinado contexto social.

Inspirada pelas ideias de Bourdieu, Norton (1995) afirma que, ao investir em uma segunda língua, o aluno compreende que, por meio dessa língua, ampliará seus recursos simbólicos e materiais que, em retorno, aumentarão o valor de seu capital cultural. Vale ressaltar que recursos simbólicos são meios como educação e amizade, enquanto recursos materiais incluem bens imóveis e dinheiro. O investimento, segundo Norton (1995), cria u ma expectativa de retorno, e um retorno capaz de garantir o acesso aos recursos previamente citados.

A noção de investimento defendida por Norton (1995), cabe lembrar, não tem a ver com o conceito de motivação instrumental. Nas palavras de Norton,

\footnotetext{
${ }^{4}$ A noção de investimento sinaliza de forma mais adequada a relação construída social e historicamente pelas mulheres à língua-alvo e seu desejo, às vezes, ambivalente de aprender e praticá-la. [tradução nossa]
} 
The conception of instrumental motivation generally presupposes a unitary, fixed, and ahistorical language learner who desires access to material resources that are the privilege of target language speakers. In this view, motivation is a property of the language learner a fixed personality trait. The notion of investment, on the other hand, attemps to capture the relationship of the language learner to the changing social world ${ }^{5}$. (NORTON, 1995, p. 17)

Nesse sentido, a noção de investimento pressupõe que, ao falar, o aprendiz está organizando e reorganizando a sua consciência de quem ele é e como se relaciona com os outros. Portanto, um investimento na língua-alvo é também um investimento na identidade social do aprendiz. O aprendiz é concebido com uma identidade complexa e dotado de múltiplos desejos que são frequentemente alterados através do tempo e do espaço.

Para desenvolver sua concepção de identidade social, Norton (1995) apoia-se em Weedon (1987 apud NORTON , 1995, p. 15), pois, segundo Norton (1995), os trabalhos de Weedon distinguem-se das outras teorias pós-estruturalistas no sentido de que o trabalho dela mantém relações entre experiência individual e poder social numa teoria da subjetividade. Para Weedon (1987, p. 21 apud NORTON, 1995, p. 15),

language is the place where actual and possible forms of social organization and their likely social and political consequences are defined and contested. Yet it is also the place where our sense of ourselves, our subjectivity, is constructed ${ }^{6}$.

Segundo Norton (1995), para o entendimento dos dados de suas pesquisas, três características da subjetividade apontadas por Weedon são importantes: a natureza múltipla do sujeito, a subjetividade como um lugar de luta e a subjetividade como algo mutável. Norton (1995) realizou um estudo longitudinal com cinco imigrantes; todas eram mulheres recém-chegadas ao Canadá, depois de completarem um curso de língua inglesa com duração de seis meses. Apesar de estarem altamente motivadas para o aprendizado, houve condições sociais particulares sob as quais elas se sentiram mais desconfortáveis para falar. Os resultados da pesquisa de Norton (1995) apontaram para o fato de que a motivação de um aprendiz de línguas para falar é mediada por investimentos que podem conflitar com o desejo de falar. Paradoxalmente, a decisão de permanecer em silêncio ou falar pode, em ambos os casos, constituir uma forma de resistência a forças sociais desiguais ou práticas sociais inescrupulosas.

Antes de apresentarmos as contribuições de Longaray (2005) que se fazem pertinentes para esta pesquisa, consideramos relevante voltar à noção de identidade social

\footnotetext{
5 A concepção de motivação instrumental geralmente pressupõe um aprendiz de línguas unitário, fixo e ahistórico que deseja ter acesso aos recursos materiais que são privilégios dos falantes da língua-alvo. Nessa visão, a motivação é uma propriedade do aprendiz de línguas - um traço fixo da personalidade. A noção de investimento, por outro lado, captura a relação do aprendiz com o mundo social mutável. [tradução nossa]

${ }^{6}$ A língua é o lugar onde formas possíveis e verdadeiras de organização social e suas prováveis consequências sociais e políticas são definidas e contestadas. Porém é também o lugar onde a nossa percepção de nós mesmos, nossa subjetividade, é construída. [tradução nossa]
} 
defendida por Norton (1995). Em textos escritos anos mais tarde, Norton (1997) faz uso do termo identidade para fazer referência ao modo como as pessoas compreendem sua relação com o mundo e com elas próprias, e como tal relação se modifica ao longo do tempo, e abandona o termo identidade social.

Quanto à identidade e aprendizagem de línguas, Norton (1997) considera que o aprendizado de uma segunda língua envolve as identidades dos aprendizes pela própria natureza da linguagem, que não é apenas um sistema de signos, mas uma prática social. Assim, ao falar, os aprendizes não estão apenas trocando informações, mas estão organizando e reorganizando o senso de quem são e de como se relacionam com o mundo. Durante esse processo, os aprendizes estão envolvidos na construção e na negociação de suas identidades.

Motivada pelos resultados das pesquisas conduzidas por Norton (1995), Longaray (2005) analisa eventos de resistência e de não participação a partir de dados gerados em uma turma de primeiro ano do Ensino Médio de uma escola pertencente à rede pública estadual do Rio Grande do Sul. Essa pesquisa durou seis meses, período compreendido entre 07 de junho a 06 de dezembro de 2004, no Instituto Estadual Dr. Barcelos, nome fictício. Foi constatado um número considerável de faltas por parte dos alunos, devido a problemas domésticos, ou abstenção durante a troca dos períodos de aula.

Longaray (2005) constatou que a maior parte das aulas observadas no Instituto Estadual Dr. Barcelos consistia em atividades que não despertavam interesse nos alunos. As atividades, restritas ao aprendizado da gramática e à tradução de textos, eram desenvolvidas por meio de um polígrafo totalmente descontextualizado, que foi elaborado pelas próprias professoras da escola. A pesquisadora verificou também que o tratamento indelicado dirigido à professora da escola era sempre produzido de forma disfarçada e respeitava certa distância em relação à posição da professora em sala de aula.

A partir de Longaray (2005), percebemos que a resistência ao aprendizado de inglês como LE constitui-se numa prática social que envolve as identidades e (a) subjetividade dos aprendizes e que põe em questão o investimento que o aprendiz apresenta.

\section{ANÁLISE DOS DADOS}

\section{Preliminares: as aulas de Inglês}

Inicialmente, queremos enfatizar que este artigo se propõe a apresentar parte de uma análise desenvolvida em dissertação de mestrado. A falta de espaço, aqui, não nos permite apresentar e analisar os dados de forma sistemática. Assim, nesta seção, 
apresentaremos aspectos metodológicos da pesquisa, parte da análise e, por fim, as possíveis conclusões.

A fim de coletarmos os dados, optamos por desenvolver um estudo de caso na mesma escola onde trabalha a pesquisadora. A escola é uma instituição que pertence à rede pública estadual do Estado de Santa Catarina. Ela atende crianças, adolescentes e jovens de classe média baixa, a maioria proveniente do mesmo município em que a escola se situa. Para a realização da coleta dos dados, utilizamos os seguintes instrumentos: notas de campo; questionário semiestruturado; gravações, em áudio, de aulas e entrevistas semiestruturadas.

A maior parte das aulas que observamos consistia na execução de atividades que não despertavam interesse nos alunos. Em sua maioria, desenvolvidas de acordo com o livro didático adotado pela escola, as atividades pareciam penosas e descontextualizadas. O livro didático adotado correspondia ao livro de Inglês distribuído gratuitamente pelo governo estadual às escolas da rede pública do Estado de Santa Catarina, e embora apresentasse textos de diversos gêneros textuais, esses textos eram muito extensos para o nível em que os alunos se encontravam e as atividades consistiam em interpretação textual e exercícios gramaticais. Muito embora a discussão sobre a qualidade do livro adotado fuja ao escopo desta pesquisa, parece-nos possível afirmar que ele consistiria em um bom material de apoio, não fosse sua utilização quase exclusiva em sala de aula.

As aulas de Inglês do Ensino Médio no Colégio São Jorge ${ }^{7}$ estavam, portanto, limitadas aos exercícios de interpretação de texto, tradução e gramática. Todos os participantes estavam acostumados às aulas expositivas; tradução e leitura feitas, quase sempre, pela professora e intermináveis listas de exercícios gramaticais e de interpretação.

Durante a exposição de conteúdos pela professora, apesar do silêncio demandado, boa parte dos alunos permanecia alheia ao que estava acontecendo. A quietude não poderia ser vista como atitude de engajamento.

Nesse contexto, as atitudes de silenciamento, não-participação explícita ou dissimulada (a simulação da conclusão de atividades, por exemplo) e indisciplina seriam caracterizadas como formas de resistência? A análise nos leva a crer que sim. E quais seriam as possíveis 'causas' da manifestação dessas atitudes?

\section{Discursos que revelam formas de resistência nas aulas de Inglês}

Analisando os discursos produzidos pelos sujeitos da pesquisa, verificamos que a atualização dos arquivos discursivos corrobora regularidades e recupera discursos que circulam, há muito, sobre a importância da Língua Inglesa na sociedade.

\footnotetext{
${ }^{7}$ Nome fictício criado para nos referirmos à escola onde a pesquisa foi desenvolvida.
} 
A grande maioria dos participantes desta pesquisa vê o conhecimento da Língua Inglesa como possibilidade de ascensão social. A falácia de que "hoje em dia um emprego de qualidade exige conhecimentos de Inglês" é compartilhada quase que unanimemente pelos entrevistados. Um dos alunos, por exemplo, forneceu a seguinte resposta quando questionado sobre o que ele achava da Língua Inglesa e de estudá-la: “Acho legal e interessante porque o inglês é muito importante. No futuro talvez eu possa precisar dele para uma viagem ou até mesmo para uma entrevista de emprego".

O discurso que ressoa na fala dos aprendizes parece retomar um discurso que circula na mídia. Em outras palavras, somos constituídos pela discursividade exterior, que não aparece como exterior, mas como naturalizada pelo processo do esquecimento referido por Pêcheux (2009), e que está reforçada pelo discurso midiático. Assim, verificamos uma relação interdiscursiva entre o desejo do aluno em aprender a LI, o imaginário da cultura exterior e o discurso midiático.

A busca pela aprendizagem de LI vai além de propósitos comunicativos e essa visão da importância da LI é muito mais histórica e ideológica do que pessoal. O sujeito é posto em uma rede interdiscursiva que traz interesses políticos, econômicos, culturais e ideológicos do Outro.

O que constatamos, no entanto, é que as práticas e os discursos desses aprendizes, produzidos em sala de aula, muitas vezes não condizem com os discursos produzidos nas entrevistas e questionários. Principalmente por meio de observação de aulas, verificamos inúmeras formas de resistência que optamos por agrupar em duas categorias, conforme sua forma de manifestação: a categoria do silêncio e a categoria do ruído.

Tomando a resistência em seu sentido denotativo, consideramos formas de resistência, neste trabalho, as práticas opositoras ao processo de ensino-aprendizagem manifestadas pelos aprendizes de LI. Assim, atitudes de não-participação; conversas paralelas; pedidos para sair da sala; situações de simulação, onde os alunos "faziam de conta" que estavam engajados numa atividade, foram as constantes formas de resistência encontradas e que, a título de simplificação, optamos por nomear atitudes de não-participação, interrupção e argumentação. As atitudes de não-participação foram agrupadas na categoria silêncio, e as atitudes de interrupção e argumentação foram agrupadas na categoria ruído. Observe o quadro: 
Quadro 1 - Formas de Resistência

\begin{tabular}{|c|c|c|}
\hline CATEGORIA & $\begin{array}{c}\text { FORMAS DE } \\
\text { RESISTÊNCIA }\end{array}$ & EXEMPLOS \\
\hline SILÊNCIO & Não-participação & 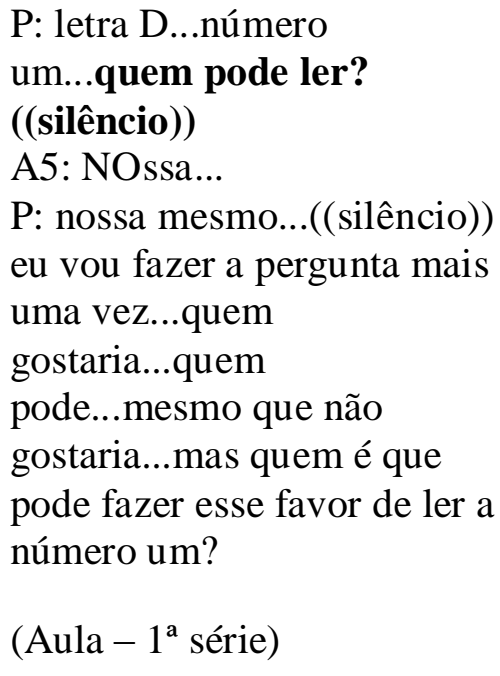 \\
\hline \multirow[t]{2}{*}{ RUÍDO } & Interrupção & 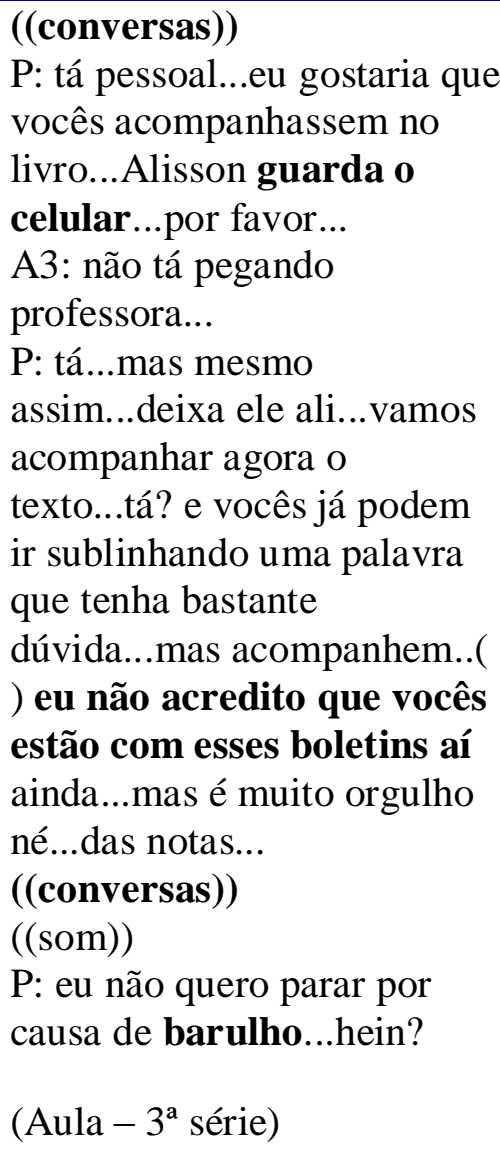 \\
\hline & & $\begin{array}{l}\text { "Não sei se faço certo ou } \\
\text { errado, mas vivo dizendo } \\
\text { pros alunos que Inglês é } \\
\text { importante, que já faz parte } \\
\text { do nosso dia-a-dia e que } \\
\text { saber Inglês pode } \\
\text { proporcionar a conquista de }\end{array}$ \\
\hline
\end{tabular}




\begin{tabular}{|l|l|}
\hline \multirow{4}{*}{ Argumentação } & $\begin{array}{l}\text { uma oportunidade melhor no } \\
\text { mercado de trabalho que está } \\
\text { cada vez mais competitivo. } \\
\text { Dias atrás um aluno do } \\
\text { terceiro ano quis discutir } \\
\text { essa questão da } \\
\text { importância do ensino de } \\
\text { Inglês dizendo que nunca ia } \\
\text { precisar disso porque } \\
\text { "queria" ser pedreiro. No } \\
\text { fim, fiquei sem palavras. } \\
\text { Acho que eu também duvido } \\
\text { dessa importância". } \\
\text { (Anotação em diário de } \\
\text { campo- Outubro/2012) }\end{array}$ \\
\hline
\end{tabular}

Encontradas algumas formas de resistência, chegamos à possível conclusão de que essas formas de resistência mantêm relações com as noções de investimento e comunidades imaginadas de Bonny Norton $(1995 ; 2001)$ e de relações de poder, de acordo com Foucault (1996; 1998; 1999; 2004; 2010b). Em primeiro lugar, a maioria dos alunos pertence a comunidades onde o Inglês não exerce influência e/ou não é necessário. Devido a esse pertencimento, o investimento despendido na aprendizagem da língua é quase nulo e daí resultam as atitudes de não-participação. Em segundo lugar, jamais seria possível verificar resistências onde não houvesse relações de poder. É porque a sala de aula está imersa em relações de poder que consideramos os subterfúgios como formas de resistência.

\section{CONSIDERAÇÕES FINAIS}

Esperamos ter contribuído para uma melhor compreensão da complexidade das relações que podem se estabelecer nas aulas de LI como LE na escola pública, e propomos que as formas de resistência sejam cuidadosamente avaliadas para que não resultem em frustração para ambas as partes: professor e alunos.

Desde o início nos propusemos a escrever sem sugerir soluções para reduzir as formas de resistência. A finalidade do artigo foi a de problematizar, fazer pensar o que nos parecia tão natural.

Nesse sentido, esperamos que aquilo que estudamos, propusemos, afirmamos, sejam motivos para novas perguntas, outras leituras, para continuar o que acreditamos inacabado, pois este trabalho só deixará de ser uma intenção se for lido e tornar-se motivo de "conversa" entre aqueles a quem se dirige de forma mais direta: aos professores e pesquisadores da linguagem. Cabe, agora, aos que lerão este trabalho produzirem suas 
próprias interpretações. Sugerimos que leiam e façam dessa leitura, e de si mesmos, algo outro, porque nós, que produzimos esta escrita, já não somos mais como imaginávamos no início; afinal de contas, ter uma identidade imutável é impossível.

\section{REFERÊNCIAS}

Denardin, F. W. (2010). Identidades, investimento e resistência - problematizando o mito de aprender inglês em uma escola de línguas. Dissertação de mestrado inédita, Centro Universitário Ritter dos Reis, Porto Alegre.

Ferreira, M. C. L. (2003). Nas trilhas do discurso: a propósito de leitura, sentido e interpretação. In: Orlandi, E. P. A Leitura e os Leitores (Org.). 2. ed. Campinas, SP: Pontes.

Foucault, M. (1996). Vigiar e punir: nascimento da prisão. 13. ed. Trad. Raquel Ramalhete. Petrópolis: Vozes.

(1998). História da sexualidade II: o uso dos prazeres. Trad. Maria Theresa da Costa Albuquerque. 8. ed. Rio de Janeiro: Graal.

(1999). História da sexualidade I: a vontade de saber. Trad. Maria Theresa da Costa Albuquerque e J. A. Guilhon Albuquerque.13. ed. Rio de Janeiro: Graal.

. (2004). Microfísica do poder. Trad. Roberto Machado. 20. ed. Rio de Janeiro: Graal.

(2010a). A ordem do discurso: aula inaugural do Collège de France, pronunciada em 2 de dezembro de 1970. Trad. Laura Fraga de Almeida Sampaio. 20. ed. São Paulo: Edições Loyola.

(2010b). A ética do cuidado de si como prática da liberdade (1984). In: Motta, M. B. (Org.). Michel Foucault: ética, sexualidade, política. Ditos e Escritos V. Trad. Elisa Monteiro e Inês Autran Dourado Barbosa. 2. ed. Rio de Janeiro: Forense Universitária, pp. 264-287.

Indursky, F. (2000). A fragmentação do sujeito em análise de discurso. In: Indursky, F; Campos, M. C. (Orgs.). Discurso, memória, identidade. Porto Alegre: Sagra Luzzatto.

Longaray, E. A. (2005). Identidades em construção na sala de aula de língua estrangeira. Dissertação de mestrado inédita, Universidade Federal do Rio Grande do Sul, Porto Alegre.

Norton, B. (1995). Social identity, investment, and language learning. TESOL Quarterly, v. 29, n. 1, pp. 9-31.

(2001). Non-participation, imagined communities and the language classroom. In: Breen, M. (Org.). Learner contributions to language learning: new directions in research. Harlow, England: Pearson Education, pp. 159-171.

Orlandi, E. P. (2002). Análise de discurso: princípios e procedimentos. 4. ed. Campinas, SP: Pontes.

(2007). As formas do silêncio: no movimento dos sentidos. 6. ed. Campinas, SP:

Editora Unicamp. 
Pêcheux, M. (2009). Semântica e discurso: uma crítica à afirmação do óbvio. Trad. Eni Puccinelli Orlandi et al. 4. ed. Campinas: Editora da UNICAMP.

Peruchi, I. B; Coracini, M.J.R.F. (2003). O discurso da cultura e a questão da identidade em livros didáticos de francês como língua estrangeira. In: Coracini, M. J. (Org.). Identidade e discurso: (des)construindo subjetividades. Campinas, São Paulo: UNICAMP, pp. 363-385.

\section{A AUTORA}

Vaniele Medeiros da Luz é mestranda em Ciências da Linguagem pela Universidade do Sul de Santa Catarina (UNISUL 2011). Possui especialização em Gramática de Texto: leitura, análise e produção (UNISUL 2010) e graduação em Letras Português/Inglês (UNISUL 2006). Atua como professora de Língua Inglesa na rede privada de ensino e como pesquisadora, atuando principalmente nos seguintes campos: discurso, educação e Língua Inglesa. É participante do Grupo de Pesquisa "Análise do Discurso: pesquisa e ensino" (GADIPE) da Universidade do Sul de Santa Catarina.

E-mail: vaniele_luz@hotmail.com 